REVISTA DE DERECHO UNED, NÚM. 25, 2019

\title{
FORALIDAD Y FISCALIDAD EN GUIPÚZCOA DURANTE LA GUERRA DE LA CONVENCION
} (1793-1795):

\author{
SPECIFIC LOCAL REGIME AND TAXATION IN GUIPÚZCOA \\ DURING THE SPANISH WAR OF THE CONVENTION (1793-1795):
}

\author{
Justo Martín Gómez \\ Doctorando de la Universidad Nacional de Educación a Distancia \\ (Facultad de Derecho) \\ justomarting@gmail.com
}

Resumen: Guipúzcoa mantenía en 1793 un régimen foral que permitía un sistema fiscal particular, a la vez que asumía una serie de obligaciones con respecto a la defensa de su frontera y de su Rey. Los pueblos mantenían, por su parte, un sistema fiscal propio para cubrir sus necesidades y contribuir, según se acordase en la Junta Provincial, a los gastos de la Provincia. Los gastos originados por la guerra fueron cubiertos tanto por los pueblos como por la Provincia, asumiendo cada uno la parte que les correspondía y valiéndose de su propio sistema de financiación.

$\mathrm{Al}$ estar la Provincia exhausta económicamente, no tuvo otra alternativa que solicitar a los Obispos de Pamplona y Calahorra que les entregasen la plata y alhajas de las iglesias y conventos de la Provincia, con obligación de reintegro, para obtener con su producto los medios económicos con que hacer frente al invasor francés, conjuntamente con el ejército del Rey. 
Palabras clave: Guerra de la Convención, 1793-1795, Financiación, Fiscalidad, Caja de Guerra, Plata, Alhajas, Iglesia, Convento, Compañías, Tercios, Guipúzcoa, Préstamos, Censo.

Abstract: In 1793 Guipuzkoa maintained a specific local regime and institutions collectively called "régimen foral" that provided For a particular tax system along with a number of customs and duties to pay for the defense of its borders and its King. Likewise, the Towns maintained their own tax system to cover their needs and contribute to the Province's expenses, as agreed by the local governmental body called the "Junta Provincial". The Towns on the one hand, and the Province on the other, each paid their share of the war expenses, using their own finances.

Due to the financial collapse of the Province, it had no other choice but to ask the Bishop of Pampelune and Calahorra to hand over the silver and jewels belonging to the local Churches and Convents, which would be returned, in order for the Province to obtain the necessary resources to finance both the war against the French invader, together with the King's army.

Key words: Spanish War of the Convention (War of the Pyrenee) 1793-1795, Financing, Taxation, War Chest, Silver, Jewels, Church, Convent, Spanish "Compañías”, Spanish "Tercios”, Guipúzcoa, Loans, Census.

Recepción original: 28/05/2019

Aceptación original: 5/11/2019

SUMARIO: I.- Introducción. II.- Financiación de la Guerra de la Convención por la Provincia de Guipúzcoa; II.1.- Caja de la Guerra; II.2.- De carácter impositivo; II.3.- La plata de las iglesias; II.4.- Donativos de particulares; II.5.- Desatención al pago de las deudas contraídas; II.6.- Reparto fogueral entre los pueblos; II.7.- Dividendo de inversiones por anticipado y reintegro de las mismas. II.8.- Dinero a censo redimible o interés. III.- Financiación de la guerra por los pueblos; III.1.- De carácter impositivo; III.2.- Renta de los propios; III.3.- Venta de propios; III.4.- Solicitar dinero a censos redimibles; IV.- Las cuentas generales de la Provincia durante los años 1792-1798. V.- Conclusiones. 


\section{INTRODUCCIÓN}

El Título XXIV de los Fueros, "De las levantadas y cosas de Guerra", en su Capítulo I dice "Que los de la Provincia no salgan de los límites de ella sin ser primero pagados de su sueldo".

La Provincia gozó siempre de este privilegio, ya reconocido por la Reyes Católicos en célula de 20 de marzo de 1484ㄹ, mandando que se les pagase el sueldo por el tiempo que voluntariamente sirviesen por orden de la Provincia y a instancias de los Reyes; es decir, solo el Rey podía solicitar a la Provincia que atendiese su petición y esta tenía que aprobarlo en Junta y dar las instrucciones para que los pueblos (o repúblicas) aprontasen las Compañías de sus naturales equipadas para la guerra, y siempre bajo las órdenes de los oficiales designados por los mismos y al mando del Coronel designado por la Provincia, que se coordinaba con el Capitán General por vía de aviso, nunca por orden. Como dice el Fuero, antes de salir de la Provincia a la tropa movilizada se tenía que haber abonado su sueldo.

Dado que cada pueblo tenía que armar y equipar a sus naturales en defensa de la Provincia y también en los casos en que el Rey solicitaba a la misma que aportase gente armada para defender territorios fuera de ella, los pueblos asumían la obligación de formar y equipar a sus naturales. Para adiestrar en el manejo de las armas y dar una mínima formación militar a su gente, por acuerdo de la Junta General se dispuso que se celebrasen "alardes" (especie de demostración pública y entrenamiento de habilidades de tiro y monta). Estos alardes eran obligatorios y, en general, se realizaban el día de San Juan, 24 de junio. El armamento y munición generalmente eran del municipio, pero, sin duda, una buena parte era privativa de los particulares. De ahí que el Título XXV de los Fueros, en su Capítulo $\mathrm{I}$, se diga "que las armas de los naturales y vecinos de la Provincia no puedan ser embargadas por deuda alguna". Esta prevención del Fuero se fundamentaba en que la Provincia, al ser frontera, debía tener las armas listas, al igual que su gente, para que, con prontitud, saliesen en defensa de la frontera ${ }^{2}$.

Cada pueblo había de hacer frente a los gastos que originaba el mantener a sus naturales en estado de alerta. Para la toma de las armas, en caso de necesidad, los municipios hacían un listado de los

1 ARAMBURU ABURRUZA, MIGUEL DE., Nueva Recopilación de los Fueros Privilegios, Buenos Usos y Costumbres Leyes y Ordenanzas de la Muy Leal Provincia de Guipúzcoa (1696), San Sebastián: FEDHAV, 2014, p. 636 [Edición M. ${ }^{a}$ Rosa Ayerbe].

2 Ibidem, Pag.645. 
hombres útiles para la guerra, de entre los 15 a 65 años, y con posterioridad los iba discriminando con determinados criterios en función de si eran aptos, solteros, casados, con o sin hijos y con otras cargas familiares. Realizada la clasificación, se hacía la llamada en función del número de milicianos que tocaba al municipio, se formaban las Compañías con sus oficiales y se reunían donde el Coronel de la Provincia acordaba.

La movilización de los vecinos tenía un coste muy importante, tanto en armas como en munición, ropa y resto del equipamiento, así como una asignación económica diaria a todos y cada uno de los hombres levantados en armas. Todo ello debe ser abonado por las arcas municipales; es decir, los pueblos tenían que hacer frente a todos los gastos originados por sus milicianos y, en los casos excepcionales en que se salía de la frontera o raya provincial, el sueldo era pagado anticipadamente por el Rey. Estos gastos eran, en ocasiones, muy cuantiosos, y puesto que los Ayuntamientos disponían de un sistema recaudador orientado a hacer frente a los gastos regulares, cuando se producen gastos excepcionales se recurría al censo y al repartimiento fogueral (este último sistema se utilizará hasta mediados del siglo XVII, en que dejó de utilizarse) entre los vecinos, previa autorización de la Junta General de la Provincia, como recogía ya la real cédula de 13 de agosto de 1509 que expidió la Reina Doña Juana $^{3}$. Dicho reparto fogueral no afectaba por igual a los vecinos, sino que respondía a su situación personal y al modo en que cada uno participaba en la vida del concejo.

Así pues, los pueblos eran un todo, que tenían que hacer frente a las necesidades propias de sus naturales y vecinos y, además, contribuir a los gastos provinciales acordados en sus Juntas, con cierta cantidad de dinero recaudado por reparto fogueral u otra vía. El funcionamiento de los Ayuntamientos no era anárquico, sino que tenía que ajustarse a sus ordenanzas, previamente aprobadas en el propio Ayuntamiento y confirmadas por el Rey y su Consejo.

Los Ayuntamientos debían cuidar de cuadrar sus cuentas y evitar el endeudamiento. Sin embargo, su fin primordial era el abastecimiento de la comunidad a la que servían y atender las necesidades comunes. Para obtener los ingresos necesarios se valían de una serie de instrumentos, tales como las sisas y los arbitrios (siempre con licencia real), si bien sus primeros recursos procedían de sus rentas y bienes de "propios" (montes, ferrerías, molinos, etc.), y de los censos

${ }^{3}$ ECHEGARAY, CARMELO DE, Compendio de las Instituciones Forales de Guipúzcoa, San Sebastián: Edición Diputación de Guipúzcoa, 1984, p.156 
suscritos con instituciones o particulares, y el repartimiento fogueral (al menos hasta mediados del siglo XVII).

El repartimiento o reparto fogueral era muy impopular y excepcional, y se aplicó cuando el gasto municipal se incrementó, especialmente en épocas de crisis económicas y bélicas. Pero dicho sistema de financiación se aplicó siempre para mejorar los sistemas regulares propios de los municipios, siendo el principal el recurso de la venta y explotación de los montes, que proporcionaron importantes ingresos a los pueblos a partir, sobre todo, de mediados del siglo XVII, con los aprovechamientos del carbón y con la revalorización de la madera que se utilizaba cada vez más en la construcción civil y pública, así como en la naval de uso civil y en la Marina de Guerra. La renta derivada de la construcción de molinos harineros, tejares y caserías municipales se convirtió, asimismo, en una buena fuente de ingresos. En caso de no haber recursos propios se acudía al reparto fogueral. Y éste se fue sustituyendo por el sistema de sisas y arbitrios, aplicado siempre con licencia real.

Con el fin de no esquilmar los montes propios y preservar los aprovechamientos para la Armada Real, todo lo relativo a los aprovechamientos y usos de montes debía contar con la autorización no solo de la Provincia, sino también del Corregidor. No hay que olvidar que al Corregidor competía, entre sus funciones, la de auditar las cuentas de los pueblos cada tres años. Esta cuestión no fue pacífica desde la publicación de la Instrucción general para todos los territorios de la Corona, de 30 de julio de 1760, que encomendó la materia al Consejo de Castilla, a la que se adscribió la nueva Contaduría General de la Corte como órgano competente. La disputa continuó hasta la real orden de 7 de mayo de 1799, que regularizó la situación hasta bien entrado el siglo XIX.

Volviendo a la situación real de las cuentas de los Ayuntamientos, hemos de decir que la mayoría de los pueblos no disponían de medios para hacer frente a los gastos originados por el equipamiento de sus milicias y otros tales como sueldos, manutención, munición, logística, etc. ${ }^{4}$ y debieron recurrir al préstamo a censo o a interés, si bien en muchos casos no encontraban quién les prestase ${ }^{5}$.

${ }^{4}$ Ponemos como ejemplo (antesala de la Guerra de la Convención) las cuentas de Villafranca de Oria, aprobadas en 1791: Ingresos = 20.661 r.; Gastos = 11.274r.; Superávit $=9.387 \mathrm{r}$. $($ real de plata $)$

${ }^{5}$ Como fue el caso de Mondragón, que solicitó dinero en la misma villa, en Bilbao, Vitoria y Burgos y no lo obtuvo, y al igual que otros pueblos pidieron a la Provincia que, como ella tenía crédito, lo solicitara ella haciéndose ellos cargo de los gastos que se generaran. 
Su situación llegó a ser dramática; sin reservas económicas, tenían que armar y sostener a sus milicias en la guerra, sus campos estaban desatendidos por falta de hombres que los trabajasen y cuidasen el ganado, por estar en la guerra, no tenían crédito para obtener dinero ni sabían a dónde recurrir a solicitar medios económicos, solo tenían a sus vecinos para hacer frente a los gastos municipales regulares, además de a los inmensos gastos de la guerra..., por todo ello debieron recurrir a los incrementos en la recaudación al consumo mediante arbitrios y sisas sobre determinados productos, que tenían un recorrido limitado en el tiempo.

A pesar del rigor del Fuero, tanto el Rey como la Provincia asumieron parte de los gastos de los milicianos locales, contribuyendo la Provincia con un real de vellón diario por cada uno de los naturales armados y el Rey con el pan y el prest diario. Y en esta Guerra el Rey también contribuyó con unos 2.000 fusiles y su munición, y la Provincia la munición y fusilería de que disponía.

\section{FINANCIACIÓN DE LA GUERRA DE LA CONVENCIÓN POR LA PROVINCIA DE GUIPÚZCOA}

\section{II.1. Caja de la Guerra}

La Junta Particular de la Provincia celebrada en Azcoitia entre los días 21 y 24 de febrero de 1793 tomó el acuerdo de constituir una "Caja de Guerra"6 a censo o interés, por un importe de 200.000 pesos $\left(=4.000 .000 \mathrm{rv}^{7}\right.$.) para hacer frente a los gastos de la guerra, y bajo la tutela de la Diputación de Guerra, de los cuales la Provincia satisfaría los gastos y la amortización correspondientes a la mitad, y la otra mitad de gastos y amortización serían asumidos fogueralmente por los pueblos. Tenemos que señalar que los pueblos tenían que hacer frente a la mayoría de los gastos de la Compañías locales que integran los 3 Tercios de la Provincia, con sus 4.600 hombres en total, que, sumados sus mandos, los marinos (en defensa de sus puertos de mar) y los milicianos de los pueblos próximos a la frontera, más los dos Batallones de voluntarios de 750 miembros cada uno, hacían un total aproximado de 8.000 hombres armados levantados por la Provincia.

Desde un punto de vista teórico, los pueblos debían asumir la mayoría de los gastos que originaban tener movilizado un contin-

6 ARCHIVO GENERAL DE GUIPUZCOA, AGG-GAO JD J 105,2 pp. 20 y 42.

${ }^{7}$ Reales de vellón 
gente tan importante de hombres armados. Los pueblos tenían el deber de proveer de armamento, munición y vestimenta a sus naturales, además de abonar una cantidad diaria a los soldados sin graduación (que, como mínimo, era de 1 real de vellón) y las cantidades debidas a la oficialidad de sus Compañías. Sin embargo, la Provincia tuvo que socorrer también a los pueblos que no tenían suficientes armas y munición para enviar a la guerra a los hombres que tenían asignados por reparto fogueral. En estos casos, la Provincia les proveía de lo necesario hasta que se acababan sus existencias, recurriéndose entonces al Capitán General, que las proporcionaba lo necesario de los almacenes reales. Por todo ello, desde la Caja de Guerra, solo se abonaban los gastos que asumía la Provincia, que necesariamente eran muy inferiores a los gastos asumidos por los pueblos; con la agravante de que dichos pueblos también tenían que contribuir a nutrir la Caja de Guerra provincial.

Las arcas de los pueblos estaban exhaustas, fundamentalmente por los gastos ocasionados, años atrás, en la ejecución de la red de caminos que por imposición real hubo de asumir en la Provincia. La penuria económica era tal que la Provincia contestó a un escrito del Capitán General, con fecha de 21 de marzo de 1793, con respecto a la inspección que el Coronel inspector hizo al puerto de Guetaria, en que aconsejó abordar algunas obras y disponer de armamento para su defensa, a lo que el Diputado General pidió que se llevase a efecto las recomendaciones del Coronel, pero que se hiciera todo a cargo de la Hacienda Real, porque la Provincia no tenía medios para ejecutar las mismas ${ }^{8}$.

El 6 de julio de 1793 la Diputación ${ }^{9}$ comunicó a todos los pueblos la constitución del Batallón de 750 voluntarios y se dieron las normas económicas y de reclutamiento:

a. Dicho Batallón estaría formado por solteros voluntarios, serían adiestrados en el manejo de las armas y serán armados y municionados por el Rey.

b. Su retribución sería de $1.500 \mathrm{rv}$. (al alistarse) y $1 \mathrm{rv}$. diario de socorro a cargo de la Caja de Guerra nutrida con los 200.000 pesos.

c. Los puertos marítimos contribuirían en lo sucesivo como cualquier otro pueblo, y no como cuando sus hombres no partici-

\footnotetext{
${ }^{8}$ AGG-GAO JD CO 50, pp. 303r.-336v.

9 AGG-GAO JD CO 051, 011v.-019v.; pp. 17-25
} 
paban en la guerra terrestre y solo se ocupaban del mantenimiento y defensa de su puerto.

d. El reparto entre los pueblos del número de voluntarios sería el establecido en el reglamento de 1703.

e. El plazo para que los pueblos hiciesen sus deberes era de 20 días, y para su ejecución se nombrarían responsables de partido.

f. Del uniforme de la tropa se ocuparían de confeccionarlo en San Sebastián.

El día 4 de noviembre de 1793 la Diputación se dirigió al Rey indicándole que la Provincia había nombrado por Coronel General de toda la Provincia a Don Ignacio de Arteaga e Idiacaiz, Conde de Corres, Marqués de Valmediano, Caballero de la Cruz de la Distinguida Orden de Carlos $3^{\circ}$, Grande de España, Gentilhombre de Cámara del Rey. La Provincia, con fecha de 8 de abril de 1794, acordó el servicio de 4.600 hombres, que con la oficialidad ascendían a unos 5.400, disponiendo en los puertos de mar a su gente "padre por hijo", así como en las plazas fuertes, a pesar de que la defensa de la Provincia suponía dejar de cultivar la tierra y sin recoger la cosecha, en un país estéril y sin medios económicos. Añadió que el Batallón de voluntarios de 750 hombres había tenido un coste, hasta entonces, de 100.000 pesos y que, para hacer frente a estos importantes gastos, estaba pensando en imponer unos moderados arbitrios sobre algunos de los géneros de consumo que llegaban a su territorio, como era el caso del cacao ${ }^{10}$. El 27 de diciembre de 1793 la Diputación comunicó a los pueblos el reparto fogueral de los 100.000 pesos necesarios y la responsabilidad que tenía cada uno de ellos. De conformidad con el acuerdo tomado el mes de noviembre anterior, a la ciudad de Fuenterrabía le habían correspondido abonar la suma de 1.242 rv. para el pago de los réditos en los términos acordados ${ }^{11}$. Con fecha de 26 de marzo de 1794 se emitió un decreto en la Junta Particular de Guerra de San Sebastián por el cual se urgió a los procuradores asistentes que acudiesen a todos los pueblos de la Provincia para conseguir 100.000 pesos (2.000.000 rv.), ofreciendo un tipo de interés del $5 \%$, con el fin de financiar los gastos de la guerra hasta la próxima Junta General de la Provincia a celebrar en julio en Guetaria. También se acordó que, una vez finalizada la guerra, se reinte-

10 AGG-GAO JD CO 051, 504v-617r; pp. 4-11.

${ }_{11}$ ARCHIVO MUNICIPAL DE HONDARRIBIA (FUENTERRABIA), AMH, Libro de Actas 1793; Signatura 139; Doc. 13.886. 
grasen a los pueblos las cantidades que hubiesen abonado del real diario que pagaban a sus soldados ${ }^{12}$.

La Diputación ${ }^{13}$ comunicó a todos los pueblos el requerimiento del Capitán General a la Diputación para que los dos Tercios que no estaban en la frontera se incorporasen con urgencia, ya que los franceses tenían hambre y en cualquier momento iban a invadir al País. Por ello se ordenó que para el 12 de junio de 1794 todos estuviesen presentes en Oyarzun y, si fuera necesario acudir a la frontera, los de Tolosa se incorporarían antes. Señaló la Provincia que hacía un gran esfuerzo y que se tenía que endeudar aún más, por lo que, de ser falsa la alarma, los Tercios deberían regresar a sus casas para recoger las cosechas. También recordó que el Capitán General debía de proveer a los pueblos de armas y municiones.

La Junta Particular de Mondragón ${ }^{14}$ ordenó el 5 de septiembre de 1794 a Don Manuel Joaquín de Furundarena (Tesorero de la Caja de Guerra de San Sebastián), que estaba presente en la villa, que se personase en la Junta con los fondos de que disponía y tratase de reconstruir el funcionamiento recaudador de la Provincia. Asimismo, ordenó pedir al Rey que concediese licencia para transformar en dinero las alhajas de plata entregadas por las iglesias e instituciones religiosas, para atender las urgencias y compromisos originados por la guerra, pues el Obispo de Pamplona había dado ya su conformidad. El 23 de octubre de 1794 la Diputación ${ }^{15}$ ordenó a la villa de Villafranca para que llevase a la Casa de la Moneda, para su fundición, la plata de las iglesias de la villa.

\section{II.2. De carácter impositivo}

A lo largo del siglo XVIII fue tomando cuerpo el concepto de "Provincia", desde un punto de vista financiero, y las necesidades financieras de la misma evolucionaron desde una posición fogueral al comienzo del siglo, hacia una posición en la que los arbitrios al consumo fueron incrementando su importancia.

Los gastos soportados por la Provincia durante los años 1792 a 1795, por la Guerra de la Convención, tuvieron su reflejo en la imposición de nuevos arbitrios al consumo. Así, en Junta General de Deva de 1792 fue preciso imponer los llamados "derechos mercanti-

12 AMH, Libro de Actas 1794; Signatura A-1-138; Doc. 13818, p.105-106.

13 AGG-GAO JD CO 051, 771r-856r; pp. 1-7.

${ }_{14}$ AGG-GAO JD CO 052, 73r-87v; pp. 21-22.

15 AGG-GAO JD CO 052, 198r -267r; pp. 11-12. 
les" sobre el cacao, azúcar, bacalao, sardina salada, arenques, grasa, canela, pimienta de Holanda y clavillo, e imponer un real en cada libra de tabaco de Virginia, dos reales en la de en polvo, cuatro en el habano y cinco reales en el brasileño. Y la Junta Particular de Mondragón ${ }^{16}$ de septiembre de 1794 , al tratar de dar una solución a las necesidades de los pueblos en sectores empobrecidos por la Guerra, y tomar las medidas extraordinarias procedentes que comentaremos al analizar la financiación de los pueblos, acordó dos medidas que favorecieron a la Diputación y a la Provincia:

$1^{\text {a }}$. Pedir al Rey que destinase a la Provincia el producto de los diezmos de las iglesias de Elgoibar y Placencia, que pertenecían al cabildo de Fuenterrabía y estaban ocupadas por los franceses.

$2^{\text {a }}$. Que del 5\% que obtuviesen los Ayuntamientos de los rendimientos de fincas y rentas se entregase el 1\% a la Diputación para destinar su importe a sufragar sus gastos.

\section{II.3. La plata de las iglesias y conventos}

Iniciada la invasión de la Provincia por los franceses, el 1 de agosto de 1794, y establecidos éstos en la línea de Tolosa-Deva, estando ya en manos de los franceses las dos ciudades de la Provincia con fortaleza (Fuenterrabía y San Sebastián) y algunas de sus villas más importantes (Tolosa, Rentería, Oyarzun, Zarauz y Guetaria); y hallándose la Diputación y los procuradores de las villas reunidas en Junta Particular en Guetaria, en manos del invasor y presos en Bayona, surgió en el otro extremo de la Provincia, el 1 de septiembre del mismo año, una nueva Diputación elegida en la Junta Particular celebrada en Mondragón entre los días 1 y 12 de septiembre de 1794, con el apoyo total de la Diputación de Álava y su Diputado General Don Prudencio María de Verastegui.

El 8 de septiembre la Junta Particular de Mondragón ${ }^{17}$, ante el peligro inminente de ocupación de la totalidad de la Provincia por parte de los franceses, acordó retirar la plata y demás alhajas de las iglesias y demás instituciones religiosas. Para ello nombró a Don Antonio de Guridi ${ }^{18}$ con orden de llevarlas a Mondragón, para su

16 AGG-GAO JD AJ I05,4; pp. 25-26.

17 AGG-GAO JD IM 4/3/71 p.170.

18 AGG-GAO JD CO 052, 088r-101v; pp. 1-2. 
traslado posterior a Vitoria y su depósito en el Convento de Santo Domingo $^{19}$. Al caer en manos de los franceses la mayoría de los procuradores de los pueblos que asistían a la Junta Particular de Guetaria en agosto de 1794, representantes de los pueblos, cuyo núcleo era el Valle de Leniz, animados por el Diputado General de Álava convocaron otra Junta Particular ${ }^{20}$, esta vez en Mondragón, para los días 1 al 12 de septiembre de $1794^{21}$, a la que asistieron la mayoría de los 18 pueblos no ocupados, conformándose con lo dispuesto varios de los pueblos ocupados.

La labor de la Diputación elegida en la Junta Particular fue ingente. Con un ejército real en desbandada y reorganizándose en Vitoria, y unas milicias provinciales que siguieron el ejemplo del ejército y se retiraron a sus casas abandonando buena parte del equipamiento, la Diputación tuvo que reorganizar la defensa de la Provincia y hacer frente a los gastos que ello conllevaba, pero sin disponer de estructura económica alguna, y con una buena parte de sus pueblos ocupados por los franceses y la mayoría de la población situada en terreno enemigo. Los pueblos libres tampoco tenían medios con qué subsistir, ya que se habían endeudado para hacer frente a la defensa de la Provincia para evitar la invasión y sus hombres, de entre 18 y 60 años, estaban movilizados en defensa de su Dios, su Rey y su Patria. Por ello, para materializar el acuerdo tomado en la Junta, la Diputación tuvo que acudir, el 15 de septiembre, a los Obispos de Pamplona y Calahorra-La Calzada ${ }^{22}$ (a cuyas Diócesis pertenecía la Provincia) a solicitar la plata y demás alhajas de las iglesias y conventos ${ }^{23}$. Hay que señalar que lo no entregado fue confiscado por los franceses como botín de guerra; es decir, si los Obispos no hubieran accedido a la petición de la Provincia, la plata y demás bienes habrían desaparecido definitivamente, ya que la plata se entregó a la Provincia con obligación de reintegro, con-

${ }^{19}$ Se comisionó al efecto a Don Fernando de Mayora y a Don José Antonio de Arizpe con orden de recogerlas por los pueblos, previa autorización de los Obispos de Pamplona y Calahorra [AGG-GAO JD AJ I05,4; p.31].

20 AGG-GAO JD AJ I05, 4.

${ }^{21}$ MIGUÉLIZ VALCARLOS, I. y otros; Estudios de Platería San Eloy 2003; Murcia 2003; pp. 369-382.

${ }^{22}$ En 1566, mediante bula de Pio V de 3 de abril, los pueblos comprendidos en el arciprestazgo de Fuenterrabía quedaron segregados del Obispado de Bayona y entraron a formar parte del Obispado de Pamplona. Con lo que a partir de esa fecha pertenecía al Obispado de Pamplona toda la Provincia de Guipúzcoa, a excepción del arciprestazgo de Leniz y las vicarías de Elgoibar, Oñate y la iglesia de San Andrés de Astigarribia, que seguían perteneciendo al Obispado de Calahorra-La Calzada [ MUJICA ZUFIRIA, S.; Geografía General del País Vasco-Navarro Guipúzcoa) Barcelona 1918, p 327].

${ }^{23}$ AGG-GAO JD CO 052, 102r-115v; pp. 17-20. 
dición que efectivamente se cumplió al finalizar la guerra, salvo lo que se entregó a la Casa de la Moneda para hacer moneda (lo fundido fue posteriormente compensado). Tampoco hay que olvidar que para los franceses la guerra era una guerra también contra la religión, y tenían derecho a quedarse con todo lo valioso como botín de guerra.

La respuesta del Obispo de Pamplona fue positiva y rápida, de tal forma que ya el 23 de septiembre de 1794 la Diputación le envió un escrito $^{24}$ agradeciéndole la entrega. De esta forma la Provincia obtuvo $1.400 .000 \mathrm{rv}$. para financiar la guerra ${ }^{25}$, según consta en el acta del Ayuntamiento de Fuenterrabía, de 21 de diciembre de 1795. Muchas de las iglesias y conventos trataron de poner a salvo sus riquezas por su cuenta, ocultándolas o sacándolas de la Provincia, en lugares que consideraron seguros. En ocasiones fueron vecinos de confianza quienes escondieron las riquezas de las iglesias y conventos (comunicándolo, o no, a las autoridades de la Provincia ${ }^{26}$ ), en un intento siempre de poner a salvo el patrimonio de sus iglesias ${ }^{27}$.

La petición de la plata y riquezas por parte de la Provincia no solo era a las iglesias, sino que también iba dirigida a los conventos existentes en la misma; e incluía no solo la plata y otros metales preciosos para entregarlos en la Casa de la Moneda ${ }^{28}$ para su conversión en moneda, sino también los frutos de las primicias, y con todo hacer frente a los gastos de la guerra. La petición a los Obispos la hizo la Diputación el día 15 de septiembre de 1794 reunida en Mondra-

${ }^{24}$ AGG-GAO JD CO 052, 116r-147v; pp. 27-29.

25 AMH; Libro de Actas 1795; Signatura 13.854; p.39.

${ }^{26}$ Un caso típico es el sucedido en la villa de Urnieta, donde Doña Josefa Antonia Fraile había ocultado el oro y la plata de la iglesia para evitar que se los llevaran los franceses. Lo comunicó a su tío, Don Andrés Fraile Burgos, y éste lo comunicó a la Diputación Extraordinaria que se celebraba en Vitoria el 12 de diciembre de 1794, al tener que huir la Diputación de Mondragón por haber sido ocupada la villa de Vergara por los franceses (distante 2 leguas de Mondragón). La respuesta de la Diputación fue que dicha señora mantuviera la custodia y que comunicara el peso de los metales [AGG-GAO JD CO 052, 346v-474r; p.2].

27 El 31 de octubre de 1794 la Diputación Provincial comunicó al Duque de la Alcudia que los franceses intentaron apoderarse de la plata del Colegio de Loyola, en Azpeitia, y que la mujer que custodiaba algunos efectos ocultos cambió el verdadero dedo de San Ignacio y colocó otro de cera en su lugar, llevándose el dedo original de San Ignacio, a disposición del Diputado General, por los vecinos, junto con otras reliquias y algunas alhajas de plata [AGG-GAO JD CO 052, 198r -267r; p.28].

${ }^{28}$ AGG-GAO JD CO 052, 198r-267r.p.28; Escrito informando al Duque de la Alcudia por el cual se solicita que S.M. se digne conceder permiso a la Provincia para transformar en dinero las alhajas de Plata para atender las urgencias y compromisos originados por la guerra. 
gón ${ }^{29}$. En Navarra al Obispo de Pamplona, Don Esteban Antonio de Aguado y Rojas, que ya había autorizado, el 5 de agosto anterior, la entrega de la plata de la catedral de Pamplona, para iguales fines, en Navarra $^{30}$, exceptuando los vasos sagrados. Lo mismo se hizo en Calahorra-La Calzada con su Obispo Don Francisco Mateo Aguiriano y Gómez, quien respondió a la Provincia el día 22 que aún no había tomado una decisión sobre el particular y que, en el supuesto de que la tomase afirmativamente, deberían excluirse de la entrega los vasos sagrados, relicarios y algún otro objeto religioso, pero poco después el Obispo accedió a lo solicitado por la Junta ${ }^{31}$. Podemos, así pues, afirmar que las instituciones religiosas guipuzcoanas colaboran en la financiación de la guerra, no sin cierto recelo en algunos casos, ya que se quedaban sin un importante patrimonio histórico que, en gran parte, no volvieron a recuperar ${ }^{32}$. Tras la orden de la Diputación de Mondragón, de 8 de septiembre, de retirar la plata y alhajas y depositarlas en el convento de Santo Domingo de Vitoria, éstas se llevaron después, en parte, a Miranda de Ebro, Palencia ${ }^{33}$ y Burgos $^{34}$.

En ocasiones fue la Diputación la que ordenó a los pueblos que enviasen la plata de sus iglesias directamente a la Casa de la Moneda en Madrid, para proceder a su conversión en moneda ${ }^{35}$. Para llevar a efecto la recogida, se designó a Fernando de Mayora y José Antonio de Arizpe ${ }^{36}$, los cuales recorrieron los pueblos y recogieron la plata en los términos autorizados por los Obispos, y pidieron también la plata depositada en Vitoria. Toda ella se había de entregar en Mondragón, al Conde de Villafranca de Gaitán, quien, a su vez, comi-

${ }^{29}$ AGG-GAO JD IM.4/3/71 p.170.

${ }^{30}$ GOÑI GASTAMBIDE J.; Historia de los Obispos de Pamplona. Tomo VIII, Pamplona, 1989, p.314.

${ }^{31}$ AGG-GAO JD IM 4/3/71, p.21.

32 En la guerra se produjo, de una forma u otra, la pérdida de una buena parte de los ajuares de metales preciosos que había en las iglesias, fundamentalmente plata, ya que o bien lo sacaron de la Provincia y no volvió por ser fundido, o los franceses lo confiscaron y se lo llevaron [Cit. MIGUÉLIZ VALCARLOS Ignacio; "Pérdida de los Ajuares de plata por parte de las Iglesias guipuzcoanas durante la francesada" Ondare, no 21, 2002, pp293-302].

33 MIGUÉLIZ VALCARLOS, Ignacio y otros; Estudios de Platería San Eloy 2003, Universidad de Murcia; Murcia,2003; pp 370.

${ }^{34}$ El día 11 de octubre la Diputación envió un escrito al Cabildo de Burgos dando las gracias por haber accedido al depósito de la plata de las iglesias de Guipúzcoa en su Catedral, y se le encargó que lo hiciese Don Jacinto de Álava [AGGGAO JD CO 052, 280r-338v; pp. 1-2].

35 Como es el caso de la orden que dio por escrito a la villa de Villafranca, el 23 de octubre de 1794, para que llevase la plata de sus iglesias a la Casa de la Moneda [AGG-GAO JD CO 052, 198r-267r; pp. 28].

${ }^{36}$ AGG-GAO JD IM 4/3/72, p.247. 
sionó a José María Echaguibel ${ }^{37}$ para que se la entregara al Agente en Corte de la Provincia, en Madrid, Blas Torres de Errazquin ${ }^{38}$, el cual lo habría de llevar a la Casa de la Moneda para su fundición y, una vez fundida y amonedada, recoger el dinero obtenido y remitirlo con urgencia a la Diputación. Pero no pensemos que los pueblos ocupados por los franceses no entregaron o escondieron la plata. Numerosos pueblos ocupados, como Urnieta, Segura ${ }^{39}$ o San Sebastián, sede principal de asentamiento de los franceses, recogieron la plata de las iglesias y la entregaron allí donde dispuso la Diputación de Mondragón ${ }^{40}$. Una vez finalizada la guerra hubo un buen número de personas que afloraron tesoros de las iglesias que los tenían ocultos.

Finalizada la Guerra, las piezas no fundidas fueron devueltas a la Provincia en la persona de su Diputado General, Conde de Villafranca de Gaitán, en Mondragón, y reintegradas a sus lugares de origen. También es justo señalar que, una vez firmada la paz, hubo ofrecimientos de entrega de los tesoros que algunos particulares habían escondido para que no cayeran en manos de los franceses, así como de iglesias e instituciones religiosas.

La plata del convento de Nuestra Señora de Aránzazu.

El primer convento que se estableció en Guipúzcoa con destino a comunidad de varones, fue el de los franciscanos de Aránzazu. Fue fundado por los frailes mercenarios hacia el año 1469, y habitado por los franciscanos desde 1491. Este convento participó muy lealmente con su contribución a la lucha contra el invasor francés, pero al estar ubicado en un monte perteneciente a la villa de Oñate, y per-

37 AGG-GAO JD IM 4/3/72, pp. 65-66.

38 AGG-GAO JD IM 4/3/72, p.170.

39 El día 16 de junio de 1775 , a un mes de que finalizara la guerra, el alcalde de Segura solicitó a la Provincia que abonase el importe del traslado de la plata desde su iglesia parroquial a la ciudad de Vitoria, en que se hizo entrega de la misma a la Provincia, y que se remitiese resguardo de la cantidad recibida [AGG-GAO JD DD 77, 1 61r-84v; pp. 7-8].

${ }^{40}$ En el caso de San Sebastián, estando la Diputación en la villa de Salinas, el 30 de enero de 1795 recibió una comunicación de Don Antonio de Ramón, vicario de la iglesia parroquial de Santa María de San Sebastián (que residía en la ciudad Santander), ofreciéndose a trasladar la plata de algunas de sus iglesias a Madrid, y se le pidió como única condición que hiciese un inventario y resguardo de la misma [AGG-GAO JD CO 052, 346v-474r; p.2]. La Diputación de Salinas, con fecha 2 de febrero de 1795, comunicó a Don Andrés Fraile que se había dado orden a dicho vicario para que le enviase la plata de que dispusiese, debidamente encajonada a Madrid [AGG-GAO JD CO 052, 346v-474r; p.2]. 
tenecer ésta un Condado no integrado en la Provincia de Guipúzcoa, entendieron los frailes que sus tesoros no debían ser entregados a la Provincia, sino que lo debían entregar al Ayuntamiento de la villa a la que pertenecían, que era la de Oñate, la cual, por su parte, contribuyó con generosidad en la defensa de la Provincia y del Rey, armando, equipando y sosteniendo a cuatro Compañías de naturales en su lucha para expulsar al invasor (Oñate se integró en la Provincia de Guipúzcoa en 1845). El convento de Nuestra Señora de Aránzazu puso a salvo sus tesoros depositándolos en el convento de San Francisco de Miranda de Ebro (Burgos). Tras la autorización de los Obispos de Pamplona y de Calahorra-La Calzada, para que la Provincia utilizase las rentas y los tesoros de las iglesias y conventos para financiar la guerra contra los franceses, y una vez que el padre guardián del convento puso a salvo los tesoros del mismo, unas 25 arrobas de plata, el 26 de septiembre de 1794 llegó al mismo la petición, por parte de la Diputación, de que hiciese entrega de las rentas y tesoros que tenía, excepto los necesarios para el culto $^{41}$. Contestó el convento a la Diputación informando que la villa Oñate ya había remitido la misma petición el 12 de noviembre, y que su alcalde defendía su prioridad, ante el guardián, señalando que el convento estaba ubicado en la jurisdicción del Condado de Oñate y que no pertenecía a Guipúzcoa, y que, además, la villa ya había colaborado y colaboraba con Guipúzcoa en la guerra con cuatro Compañías de sus naturales.

En la reunión de la Diputación extraordinaria celebrada en Vitoria el 12 de diciembre de 1794, ya citada, se acordó remitir un escrito $^{42}$ al General de los franciscanos, Fray Juan Compani, solicitando la cesión de la plata que había en los conventos de ambos sexos en la Provincia, incluso en el Santuario de Aránzazu, y transmitiéndole que el padre Definidor General, fray Juan de Izaguirre, había dado la orden de entrega de la plata a la Provincia.

El guardián de los franciscanos era más proclive a acceder a la petición del alcalde de Oñate, en base a que siempre había socorrido al convento y a que el Obispo de Calahorra-La Calzada había accedido a entregar las rentas y la plata de la iglesia de San Miguel de Oñate a su alcalde. Ello se comunicó al padre General de la Orden

${ }^{41}$ AGG-GAO JD CO 052, 149v-191v; pp. 1-3. Escrito al Definidor General de la Orden franciscana, Don Juan de Izaguirre, diciendo que se pusiese a disposición de la Diputación, con obligación de reintegro, la plata que hubiera en el Santuario de Aránzazu, a excepción de los vasos sagrados.

${ }^{42}$ AGG-GAO JD CO 052, 346v-474r; p.2. 
para que decidiese lo procedente y ordenase inmovilizar el tesoro ${ }^{43}$ y elevar el asunto al Rey para que, mediante el Fiscal General del Reino, dispusiese que los tesoros se entregasen a la villa de Oñate. Estos fueron reintegrados al convento de Aránzazu, desde el convento de San Francisco (posiblemente de Miranda de Ebro), el día 25 de diciembre de 1795, una vez finalizada la Guerra ${ }^{44}$. Ese mismo día 25 la Diputación escribió al General de los franciscanos para informarle de que, a pesar de las instrucciones que dio y de las dadas por el padre Definidor, la plata del santuario de Aránzazu fue entregada a la villa de Oñate por el padre Arrazola, por lo que le rogaba que comunicase a la villa para que la entregase a la Provincia ${ }^{45}$.

Con posterioridad, y una vez finalizada la Guerra, el convento tuvo que entregar plata a la villa de Oñate para hacer frente a los gastos originados por aquélla, por importe de 109 libras (cuyo valor ascendía a 34.520 reales y 17 maravedís).

La Plata de otros conventos masculinos.

En Guipúzcoa había, en 1794, 19 conventos masculinos de distintas Órdenes religiosas ${ }^{46} \mathrm{y}$, al igual que las iglesias, todos ellos fueron saqueados por las tropas invasoras. Muchos de ellos sirvieron, además, de alojamiento a las mismas. Todos los conventos tenían instrucciones de sus superiores de entregar a la Provincia sus riquezas, en los términos ya señalados, a excepción de los vasos sagrados. Los conventos de Mondragón y Zarauz entregaron con presteza sus tesoros a la Provincia. En el caso del convento de Mondragón, éste realizó el depósito en el convento de San Francisco de Miranda de Ebro, y en febrero de1795 ${ }^{47}$ entregó a la Provincia 332,5 onzas de plata. Por su parte, ante la premura de la invasión en Tolosa, los franciscanos del convento de la villa no tuvieron tiempo de salvar apenas nada de su riqueza y, en un intento de impedir que los franceses sacasen provecho de la misma, la ocultaron en la bóveda del convento, pero un chivatazo del vecino Domingo de Sarasola, que vivía cerca del convento, alertó a los franceses.

43 ARCHIVO MUNICIPAL DE OÑATI (OÑATE), AMO, F.III-1-5. Caja 1127. Exp18. Carta a Oñate.

${ }^{44}$ ARCHIVO DEL CONVENTO DE ARÁNZAZU (AC, Sección XIV, Alhajas de la Virgen, Libro IX

45 AGG-GAO JD CO 052, 346v-474r; pp. 5-7.

46 MUJICA ZUFIRIA, S., Geografía del País Vasco Navarro, Guipúzcoa, Barcelona, 1918 , p.336

${ }^{47}$ AGG-GAO JD IM 4/3/72, p. 233. 
Sin duda alguna cada convento tiene su historia, y en la mayoría de los casos no nos ha llegado el relato de las penurias que tuvieron que pasar, al ver que todo por lo que habían trabajado y, sobre todo, su Dios, su Rey y su Patria estaban siendo ultrajados por unos invasores bárbaros que no respetaban lo que más valoraba la sociedad guipuzcoana de la época: su religión.

Los conventos, en su gran mayoría, quedaron abandonados por sus moradores, temiendo por sus vidas, y siguiendo las instrucciones de sus superiores, huyeron hacia otros lugares donde habían establecido conventos de su misma Orden, llevándose consigo, en general, lo mínimo para el viaje y en algunos casos, algo de valor para una mísera subsistencia, con el riego de ser asaltados durante el traslado y en su destino por las muchas bandas de saqueadores que había en aquella época.

En los conventos que no se evacuaron en su totalidad, los que se quedaron sufrieron grandes vejaciones, y para su subsistencia tuvieron que acudir a los vecinos. Los Ayuntamientos también socorrieron a los frailes, y especialmente al finalizar la Guerra para que reiniciasen sus actividades. No hay que olvidar que la invasión de Guipúzcoa comenzó el día 1 de agosto de 1794, y la Paz de Basilea se firmó el 22 de julio de 1795, y que Vitoria capituló el 30 de julio de 1795, cuando ya se había firmado la Paz y los ejércitos franceses continuaron su avance victorioso hasta cruzar el río Ebro. Estabilizando el frente en las orillas del río Ebro, los franceses enviaron un emisario a las tropas del ejército español comunicándoles la buena nueva de la firma de la Paz, y esto se produjo el día 4 de agosto, comenzando la retirada los franceses el 20 de agosto de 1795.

\section{La Plata de los conventos femeninos}

Los conventos femeninos que había en esas fechas en Guipúzcoa ascendían a $23^{48}$, y también vieron cómo se perdían sus ajuares de plata por el saqueo de los franceses, por la obligación de entrega a la Diputación y por la necesidad de venderlo para subsistir en el exilio. Ante la inminente invasión, los diferentes conventos existentes en la Provincia trataron de poner a salvo sus riquezas, poniéndolo a buen recaudo en conventos de la Orden fuera de la Provincia, al igual que las propias religiosas, que se refugiaron en conventos de su Orden de Álava o Castilla. En tales casos llevaron sus riquezas, tanto para po-

48 MUJICA ZUFIRIA, S.; Geografía del País Vasco Navarro, Guipúzcoa; Barcelona,1918, p.336.

(C) UNED. Revista de Derecho UNED, núm. 25, 2019 
nerlas a salvo como para garantizar su sustento, pues sus rentas se quedaron en su lugar de origen.

Pero no todas tuvieron la misma suerte, y así las concepcionistas de Azpeitia no pudieron sacar sus riquezas de la Provincia porque se lo impidió el Ayuntamiento, por lo que no tuvieron otra alternativa que esconderlo, siendo encontrado por los franceses en octubre de 1794. Algo parecido sucedió con las clarisas de Azcoitia pues, al no poder llevarse sus ajuares de plata, lo escondieron en el altar mayor de la iglesia y lo encontraron los franceses, y ante la petición de la Diputación de que lo aportasen para hacer frente a los gastos de guerra éstas manifestaron lo sucedido. Otro tanto sucedió con las clarisas de Tolosa, las cuales ante la petición de la Diputación, respondieron que con la urgencia de la salida no pudieron llevarse más que una pequeña parte de sus alhajas y que la necesitaban para su subsistencia, y solicitaron ayuda a aquélla por falta de recursos. Pero el 26 de enero de 1795 la Diputación de Salinas comunicó a las monjas de Tolosa en el exilio que ellas también tenían que entregar la plata con reintegro, de conformidad con lo acordado por el padre Definidor $^{49}$. La situación de las religiosas llegó a ser tan precaria que los conventos de las concepcionistas de Mondragón y Segura, y las clarisas de Elgoibar, Zarauz y Vergara, y las de ambas Órdenes de Oñate, debieron solicitar ayuda a sus Ayuntamientos para poder subsistir.

Relato de lo sucedido en convento las clarisas de Azcoitia en $1794^{50}$

Disponemos de un texto manuscrito, inédito hasta la fecha, catalogado recientemente y de autor desconocido, que narra los hechos más importantes acaecidos en ese convento en años anteriores y algunos posteriores a la invasión. La base del texto está conformada por los documentos que recogieron del suelo después de ser esparcidos por los soldados franceses, que los encontraron y sacándolos de su escondite y los destruyeran parcialmente. El texto describe que, una vez que los franceses ocuparon, en tan solo 9 días, la Provincia de Guipúzcoa hasta Tolosa, incluida esta villa, la mayoría de las religiosas de otros conventos guipuzcoanos abandonaron sus casas. Las monjas agustinas de Hernani, en su tránsito hacia el exilio, se presentaron para hacer noche en su convento sin previo aviso, causando ciertos problemas pues no cumplían las reglas de su Orden.

49 AGG-GAO JD CO 052, 346v-474r; pp. 18-19.

50 Archivo Convento Clarisas de Azcoitia. 
Según el documento, el 28 de agosto de 1794 pasaron por Azcoitia varios regimientos de soldados franceses, en tránsito hacia la villa vizcaína de Ondarroa la cual incendiaron. Ante la gravedad de la situación creada por la invasión, el General de la Orden, José Joaquín Compani, ordenó al padre Provincial que todas las religiosas de su filiación se internaran en la Península, pero estas órdenes no llegaron al convento de Azcoitia, porque el servicio de correos no funcionaba ya. Que el Gobierno francés emitió una orden mediante la cual se internaría en la ciudadela de Bayona a todos los clérigos, religiosos, religiosas y personas pudientes de la Provincia. El 4 de septiembre la villa de Azcoitia insistió en que las religiosas siguieran en el convento, indicando que 8 días antes habían pasado las tropas francesas por la villa y las monjas no fueron molestadas. A pesar de lo señalado, las monjas iniciaron el 5 de septiembre, con dolor y acompañadas del vicario, el traslado al convento de Santa Isabel en Gordejuela (Vizcaya). El viaje costó a la comunidad 4.998 reales. La mayor parte de los enseres se quedaron en el convento a cargo de José Manuel Zuazola y Cigorraga, que guardó los papeles del archivo detrás del retablo del altar mayor, pero los soldados franceses dieron con los papeles, los esparramaron y, sin duda, se perdieron muchos.

Dado los tiempos revueltos que se vivían previamente a la invasión, y como medida cautelar, las religiosas trasladaron los efectos de sacristía, menos los vasos sagrados y alhajas, a la villa de Vergara, considerado lugar seguro, pero dicho tesoro cayó en manos del enemigo en su mayor parte. Esos vasos sagrados y las alhajas que no depositaron y aún conservaban, llevaron las monjas a su exilio. Al solicitar la Provincia al padre General de la Orden la plata de las iglesias de su jurisdicción, a la que accedió con cláusula de reversión, las religiosas entregaron en Mondragón diversas piezas de plata, por un peso total de 450 onzas. El peregrinaje de las monjas no terminó, pues fueron asaltadas por unos bandidos. Considerando que no estaban seguras, se trasladaron al convento de la Purísima Concepción, en Bilbao. Cuando las tropas francesas se acercaron a Bilbao, el 14 de julio de 1795, salieron hacia el convento de Santa Clara de Castro Úrdales para irse, poco más tarde, al convento de Santa Clara de Santander. Dado que el Gobierno francés había pasado a manos de los moderados y se había publicado un decreto mediante el cual se urgía a los huidos que regresasen y tomasen nuevamente posesión de sus propiedades, bajo amenaza de ser confiscadas, cuatro de sus religiosas decidieron volver a Azcoitia con su vicario, para tomar posesión del convento, y a los dos tres días de su llegada recibieron la noticia de la firma de la Paz. 
Las monjas, a excepción de las fallecidas, se reunieron nuevamente en Azcoitia el día de San Miguel, 29 de septiembre de 1795, en un convento muy dañado que hubo que reconstruir, viviendo ínterin las monjas en el edificio del hospicio. Las obras de rehabilitación importaron 60.000 reales. Este es un ejemplo de lo que realmente sucedió en la gran mayoría de las iglesias y conventos de Guipúzcoa.

Resumen final relativo a la plata de las iglesias y conventos

Como hemos comentado, las autorizaciones de los Obispos de Pamplona y Calahorra-La Calzada y de los responsables de las distintas Órdenes religiosas, tanto masculinas como femeninas, impusieron como condición que la plata que entregasen a la Provincia debía ser con obligación de reintegro, es decir, que terminada la guerra se les debería devolver la que no se hubiera usado o reintegrar su valor en el supuesto de haberse fundido. La valoración de la plata fundida en beneficio de la Provincia de Guipúzcoa ascendió a la suma de 1.400.000 rv., según consta en el Libro de Actas del Ayuntamiento de Fuenterrabía de 21 de diciembre de $1795^{51}$. Esta cantidad fue abonada por la Provincia, después de infinitos requerimientos, por acuerdo suscrito a mediados del siglo XIX. La cantidad resulta a primera vista un poco corta, teniendo en cuenta el importante número de iglesias y conventos existentes en la Provincia. Pero hay que tener en presente que gran parte de las iglesias y conventos de la Guipúzcoa ocupada fueron saqueados por los franceses, que una buena parte de la plata se ocultó y no fue entregada y, por último, que al finalizar la guerra fue reintegrada a sus titulares una buena parte de la plata que se había entregado.

Ignoramos si los 1.400 .000 rv. responden al valor de reposición de las joyas fundidas o es el valor que percibió la Provincia, descontados todos los costes y comisiones atribuibles, pero nos inclinamos a pensar que la Provincia percibió esa cantidad neta. El valor de reposición de lo entregado a la Provincia y no devuelto a sus titulares, según valoración estimada por expertos a los que hemos consultado, perfectamente podría representar tres veces más que el valor percibido por la Provincia, y para ello se parte de las bases siguiente:

$-1 \mathrm{r}=2 \mathrm{rv}$

- Un real de a $8=8 \mathrm{r} .=16 \mathrm{rv}$.

51 AMH, Libro de Actas 1795; Signatura 139; Doc. 13854, p.39. 
- El real de a $8=25$ gr. de plata

— De $1 \mathrm{~kg}$. de plata salen 40 reales de a $8(1.000: 25=40)$

-40 reales de a $8=320 \mathrm{r} .=640 \mathrm{rv}$

Por consiguiente, de $1.000 \mathrm{~g}$. (1 kg.) de plata salían 40 monedas de real de a 8 , que equivalían a 640 rv.

Los costes añadidos por recopilación, almacenamiento, transporte, comisiones y transformación en moneda y su distribución deberían ser, como mínimo, igual al importe percibido por la Provincia de $1.400 .000 \mathrm{rv}$.

A la vista de lo anterior, se puede hacer una estimación aproximada de que la Provincia fundió plata en una cantidad de $4.375 \mathrm{~kg}$ $(1.400 .000 \mathrm{rv}: 320 \mathrm{rv} / \mathrm{kg}=4.375 \mathrm{~kg}$ de plata (se ha hecho un cálculo conservador en cuanto a los costes, lo probable es que se hubiera fundido entre el 10 y el $20 \%$ más, es decir unos $5.000 \mathrm{~kg}$. de plata).

\section{II.4. Donativos de particulares.}

No fue despreciable la financiación de la Guerra mediante donativos de prohombres, guipuzcoanos o no, que ocupaban cargos importantes tanto dentro de la Provincia como fuera de ella. Estos donativos fueron entregados espontáneamente por muchos de ellos, pero también a instancias de la propia Provincia, que movilizó todos sus medios, obteniendo importantes donativos provenientes de guipuzcoanos residentes en Cádiz, Sevilla y Madrid ${ }^{52}$ fundamentalmente.

La Caja de Guerra acordada en Azcoitia tendría unos fondos de 200.000 pesos a censo del 5\% de los cuales 100.000 serían a cargo de la Provincia, que abonaría intereses y capital, y los otros 100.0000 pesos a cargo de las repúblicas, según reparto fogueral. Esta Caja de Guerra se constituyó antes de la declaración de la Guerra con Francia, la cual se declaró, primero por Francia el día 7 de marzo de 1793, y después por España el día 23 del mismo mes, es decir unos días más tarde. Una vez declarada la guerra se iniciaron las hostilidades entre las partes. Lo verdaderamente relevante es que la invasión a Guipúzcoa se produjo el día 1 de agosto de 1794, y pocos días más tarde buena parte de la Provincia estaba ya bajo dominio fran-

52 Mención especial merece el donativo del Marques de Narros, prohombre de la Provincia, por un importe de 10.000 pesos que ofreció en la Junta Particular de Azcoitia de febrero de 1793, cuando la Junta acordó crear una Caja de Guerra.

(C) UNED. Revista de Derecho UNED, núm. 25, 2019 
cés y sus instituciones provinciales anuladas, con la mayoría de sus representantes prisioneros en Bayona, alguno colaborando voluntariamente y otros custodiados en sus puestos. Lo comentado tiene su relevancia, en el sentido de que las instituciones existentes en la zona ocupada por los franceses quedaron anuladas, y si había medios económicos estos fueron confiscados por los franceses; mientras que en la zona no ocupada renacieron las instituciones, pero se encontraron absolutamente sin fondos y con unos pueblos desfondados económicamente y sin apoyo material de la Corona. De ahí la importancia de la obtención de recursos que realizó la Diputación de Mondragón, pues cuando ofreció pagar a los naturales alistados en las Compañías contra los franceses un real diario, su compromiso fue "mientras haya dinero para ello".

La Provincia tenía en distintas partes de reino un buen número de personajes ilustres a los que no se les olvidó su origen, y a los que la Provincia recurrió solicitando una aportación económica a fin de paliar, en alguna medida, las calamidades que sufrían los que habitaban en ella y, sobre todo, hacer frente al invasor. Para ello la Diputación surgida de la Junta Particular de Mondragón de septiembre de 1794 tomó la iniciativa de elaborar un listado de personajes de la Provincia exiliados, con la finalidad de dirigirse a ellos directamente o a través del Agente en Corte o terceros, en solicitud de ayuda. En la Junta Particular realizada en Salinas los días 24 y 25 de enero de 1795, en la sesión de la mañana del 25 de enero se informó en los términos siguientes:

"Los señores Diputados Generales dieron cuenta de los medios de que se han valido para atender a los gastos que tiene la Provincia con motivo de la presente Guerra, manifestando que uno de ellos había sido el circular oficios a los hijos oriundos del País, exponiéndoles los servicios que han hecho por sus naturales y el estado a que se ha visto reducido; exhortándoles con este motivo a que suministren los donativos y socorros voluntarios que les dicte su patriotismo y proporcionen sus respectivas facultades".

Por orden de la Diputación, de 2 de octubre de 1794, se elaboró una relación de hijos de la Provincia a los que pedir ayuda económica $^{53}$. La Diputación en Salinas dirigió, el 26 de enero de $1795^{54}$, una orden al Agente en Corte para que dirigiese 30 escritos a otros tantos guipuzcoanos en el exterior para que socorriesen a la Provincia en estos momentos tan difíciles. También le remitió la lista de

53 AGG-GAO JD IM3 04 076,3 A 226r-233r; pp. 36-39.

${ }^{54}$ AGG-GAO JD CO 052, 346v-474r; pp. 15-16. 
guipuzcoanos a los que se había dirigido directamente para no duplicar peticiones. La Diputación, por su parte, envió escritos a personas oriundas de la Provincia domiciliadas en unas 10 provincias $^{55}$.

Entre las decenas de documentos encontrados citaremos que el 2 de febrero de $1795^{56}$ la Diputación de Salinas requirió a los 18 pueblos de la línea para que abonasen el donativo, los caudales sobrantes y las primicias cedidas por los Obispos. Y el 9 de febrero la misma escribió a Don José Antonio de Otamendi agradeciendo su donativo de 300 pesos $^{57}$.

\section{II.5. Desatención al pago de las deudas contraídas.}

Antes de la Guerra la Provincia había asumido importantes deudas, fundamentalmente como consecuencia de haber acometido la construcción de una importante red de caminos a mediados del siglo XVIII, y el mantenimiento de los ya existentes construidos y mantenidos por los pueblos en sus respectivos tramos. Al ser la Provincia transitada por miembros de la familia Real en sus caminos hacia $\mathrm{Pa}-$ rís y Madrid, obligó a que estos estuvieran en buen estado ${ }^{58}$.

En 1782 la Junta Provincial acordó construir un camino de coches desde la entrada a la Provincia por Álava, en el punto de Salinas, pasando por Mondragón y Vergara hasta Irún, aprovechando el camino antiguo en todo lo que fuere posible. El coste del proyecto ascendía a 7.500.000 de reales, con una longitud de $177 \mathrm{~km}$. En 1788 se establecieron seis barreras para el cobro del peaje con que financiar la construcción y atender a su mantenimiento ${ }^{59}$. El coste de las obras mencionadas, más otras obligaciones que la Provincia debía atender con la Corona, vaciaron las arcas de los pueblos y la de la Provincia, que se endeudaron fuertemente; endeudamiento que se

55 El día 26 de enero de 1795 la Condesa de la Cañada contestó que su posición económica no le permitía atender la solicitud realizada en ese momento [AGG-GAO JD CO 052, 346v-474r; pp 20-21].

56 AGG-GAO JD CO 052, 346v-474r; pp. 27-28.

57 AGG-GAO JDCO 052, 504v-575v; p.3.

${ }^{58}$ Las principales vías eran tres: $1^{\mathrm{a}}$-- El camino que desde Álava pasaba por el túnel de San Adrián y se dirigía a Tolosa, San Sebastián y, por Irún, a Francia. 2a .El camino que desde Álava entraba en Guipúzcoa por Salinas, pasaba por Oñate y Beasain, y conectaba allí con el anterior camino hacia la frontera. $3^{\mathrm{a}}$.- El camino que desde Pamplona entraba en Guipúzcoa por Berástegui hasta Tolosa, en donde empalmaba con el camino hacia la frontera con Francia.

59 Hay que señalar que la Junta tomó el acuerdo de realizar el camino de coches que conducía a Pamplona en la parte guipuzcoana, y se ejecutó entre los años 1788 y 1790 , con un coste de 846.412 reales y con una longitud de $12 \mathrm{~km}$.

(C) UNED. Revista de Derecho UNED, núm. 25, 2019 
acrecentó con los gastos de los preparativos de la Guerra y el coste de la misma. Todo ello refleja la calamitosa situación económica y financiera de la Provincia y de los pueblos, que no podían hacer frente al pago de los intereses de la deuda contraída, ni podían hacer frente a la amortización de los créditos que habían obtenido. No olvidemos que la Provincia se nutría fundamentalmente de las aportaciones que fogueralmente hacían los pueblos, previo acuerdo de la Junta. Los pueblos no podían aportar porque estaban muy endeudados, en buena parte por la política de la Provincia de hacer y mantener los caminos. Y hay que tener en cuenta que una Provincia con una población de unos 120.000 habitantes tenía la mayor parte de su fuerza productiva dedicada a la guerra y no a la producción. Y que en una Provincia tan pequeña y pobre había asentados dos ejércitos de más de 15.000 hombres cada uno. Los medios eran escasos y la mayoría de sus hombres útiles se hallaban en pie de guerra.

Del análisis de las cuentas anuales de los años 1792, 1793 y 1794 vemos que la Provincia estaba endeudada, de una forma casi constante, en unos 3.800.000 rv, y que por dicho importe abonaba unos $65.000 \mathrm{rv}$ anuales. De lo que resulta el hecho de que la media de los intereses que abonaba a sus acreedores era del 1,7\% aproximadamente. Dicho endeudamiento se debió, en su mayor parte, a la construcción de los caminos a que antes nos hemos referido.

Durante la ocupación parcial de los franceses de la Provincia, esta estaba dividida en dos partes: la ocupada y la libre. La ocupada, sin instituciones locales ni provinciales, aunque colaboraba con los franceses un Diputado y alguna persona relevante más; y la parte libre, sin medios económicos y con la ingente tarea de reconstituir las instituciones provinciales y locales, así como de organizar la defensa y reconquista de la Provincia con un ejército real en desbandada y desorganizado y con unas milicias de naturales sin medios y desorganizadas. En esta situación, la parte ocupada no reconocía deuda alguna, y la no ocupada no abonaba deuda alguna porque, entre otras razones, no tenía medios ni para la subsistencia, aunque reconocía las deudas, obligándose a pagar cuando hubiere medios. Sin embargo, una vez que la situación se normalizó después de firmada la paz, se pagaron los intereses de los dos años no abonados, pero no se abonaron los intereses de los intereses no abonados. 


\section{II.6. Reparto fogueral entre los pueblos.}

Con la visión que tenemos ahora, más de 200 años más tarde podemos afirmar que Guipúzcoa llevó siempre una contabilidad general, auditada y caracterizada con ciertas particularidades, a la que se asignaba una serie de gastos corrientes y unos ingresos determinados. Cuando la Provincia iniciaba alguna acción singular, se abría una cuenta específica a la que se le asignaban sus ingresos correspondientes. Ello nos permite afirmar que la Provincia tenía varias cajas: Caminos, Sacas, Guerra, Expósitos y otras. En el caso de la Caja de Guerra, la Junta Particular de la Provincia celebrada en Azcoitia entre los días 21 y 24 de febrero de 1793 tomó el acuerdo de constituir una Caja de Guerra ${ }^{60}$ a censo o interés, por un importe de 200.000 pesos $(=4.000 .000 \mathrm{rv})$, para hacer frente a los gastos de guerra, y bajo la tutela de la Diputación de Guerra, de los cuales la Provincia debería satisfacer los gastos y amortización correspondientes a la mitad, y la otra mitad de gastos y amortización sería asumida fogueralmente por los pueblos.

Con independencia de que la cantidad asignada a esta Caja era a todas luces insuficiente para una guerra que tuvo una duración de 2,5 años, parece que las previsiones eran que la guerra durase mucho menos y que, además, sería victoriosa, ya que los Capitanes Generales de Guipúzcoa se jactaban de que su frontera era infranqueable. Pero la realidad fue muy diferente y Guipúzcoa fue invadida, al igual que Vizcaya y Álava.

La parte económica a la que debía hacer frente la Provincia tenía su financiación por los medios acordados por la Junta de Azcoitia; sin embargo, el 50\% de la Caja de Guerra que debía sufragarse por los pueblos debía hacerse por reparto fogueral, con lo que cada pueblo asumía la responsabilidad que por reparto les correspondía de los 10.000 pesos anuales a los que globalmente debían hacer frente.

Como la guerra en Guipúzcoa debía ser defensiva (según los planes acordados en el Consejo de Estado de febrero de 1793 que presidió el Rey y por el que Aranda fue preso y desterrado), lo normal es que los guipuzcoanos pensasen que la Provincia estaría a salvo de la ocupación francesa. Es más, los Generales no tenían ningún plan de defensa de la Provincia que fuera más allá de Hernani, a escasas 3 leguas de la frontera, donde habían previsto un segundo cordón defensivo de forma cautelar, pero en la convicción de no ser necesario, ya que la frontera era inexpugnable.

${ }^{60}$ AGG-GAO JD J 105, 2; pp. 20-42. 
Como las cosas no iban bien y los pueblos debían hacer mucho mayor esfuerzo, éstos comenzaron a no poder hacer frente a sus compromisos de ingreso en la Caja de la Guerra ${ }^{61}$ y ésta quedó bloqueada por la invasión, dándose el caso de que su tesorero se refugió en Zeanurí, localidad de Vizcaya, y comenzó a servir a la Diputación de Mondragón al organizarse esta.

Joaquín Furundarena ${ }^{62}$, nombrado en la Junta Particular de Azcoitia depositario del contingente fogueral con destino a gastos de Guerra, comunicó a la Diputación de Mondragón (a la que había sido llamado de su exilio en Vizcaya) que había pueblos que habían contribuido en estos años y otros no, por estar ocupados, y pidió instrucciones.

El Diputado General mandó un escrito a los pueblos urgiéndoles para que aportasen el donativo para los gastos de guerra acordado en la Junta de Deva. De no hacerlo, tomaría las medas precisas, pero los pueblos alegaron no tener fondos.

El 26 de julio de 1796 se recordó a la villa de Tolosa que el 27 de diciembre de 1793 se comunicó a los Pueblos el reparto de los 10.000 pesos acordados en Junta Particular, de los que a la citada villa le correspondieron 5.329 reales y 8 maravedís. Posteriormente, en Junta General de Cestona se acordó que el abono se hiciera en dos plazos uno en San Juan y otro en Navidad, y al no haber pagado su parte la mayoría de los pueblos el tesorero comunicó al Diputado General que no podía hacer frente al pago de los intereses comprometidos por la Diputación, por lo que instó a los pueblos a que cumpliesen sus compromisos para que la Diputación pudiese cumplir los suyos.

\section{II.7. Dividendo de inversiones por anticipado y reintegro de las mismas}

Analizadas las cuentas de la Provincia y de los pueblos de referencia, en ninguna de ellas hemos encontrado los gastos que hicieron aquéllos para defenderse de los franceses. En algunos casos se estima que no se contabilizaron, en otros se perdieron y otros se destruyeron voluntariamente. Lo que sí sabemos es que la Diputación

${ }^{61}$ El 18 de mayo de 1796 la ciudad de Fuenterrabía, al ser requerido al pago de los compromisos asumidos con la Caja de Guerra, dijo haber dado orden de pago puntual, a pesar de ser acreedora de la Caja de Guerra [AMH, Libro de Actas 1796; Signatura 139].

${ }^{62}$ AGG-GAO JD DD 77.1, 85r-115v; pp. 7-9. 
de Mondragón carecía en sus inicios de los más mínimos medios económicos, teniendo que recurrir a los dividendos producidos por la Real Compañía de Caracas y a la venta de todo o parte de su participación en la misma.

En la Junta Particular de Azpeitia de febrero de 1793 se acordó solicitar al Rey que ordenase a la Dirección de la Real Compañía de Filipinas para que entregase a la Provincia 50.000 pesos de réditos y capital con que hacer frente a los pagos que habían de originarse de forma inmediata en la guerra ${ }^{63}$. El 23 de septiembre del mismo año la Diputación ${ }^{64}$ urgió al Agente en Corte para que facilitase la obtención del dividendo de la participación que tenía la Provincia en dicha Compañía, y para que buscase dinero en la Corte, con la finalidad de hacer frente a los gastos del Batallón que había formado, pues había muchos voluntarios que no se podían integrar en él porque la Provincia no tiene dinero. El 28 de septiembre de 1794 fue la propia Diputación de Mondragón ${ }^{65}$ la que se dirigió por escrito a la citada Compañía al objeto de remediar su falta de medios económicos.

El Agente en Corte remitió a la Provincia las "vitelas" de las acciones que poseía Guipúzcoa en la Compañía, a manos del tesorero de la Provincia Don Francisco Javier de Leizaran, que entonces estaba preso en Bayona y su casa ocupada por los franceses. Por ello hubo de solicitar que se le entregasen nuevas "vitelas", con el compromiso de devolverlas si recobraban aquéllas. El 27 de febrero de 1795 la Diputación ${ }^{66}$, asentada en Salinas, remitió poder al Agente para asistir a la Junta de la Compañía y cobrar los primeros dividendos.

\section{II.8. Dinero a censo redimible o interés}

La Provincia tenía muchos gastos, al igual que los pueblos, y su crédito era muy reducido, a pesar del alto tipo de interés que estaba dispuesta a pagar para financiar las necesidades excepcionales derivadas de la guerra. Su "prima de riesgo" era muy alta, y su situación se agravaba al no haber prestamistas con fe suficiente para asumir el riesgo de la inversión. Por ello, hubo de suplicar ayuda al Rey y buscar en la Corte medios económicos, que solo obtuvieron a "cuenta-

${ }^{63}$ AGG-GAO JD J105,2 p.21.

${ }^{64}$ AGG-GAO JD CO 051, 039r-235r; pp. 17-19.

65 AGG-GAO JD CO 052, 149v-191v; pp. 18-20.

${ }^{66}$ AGG-GAO JD CO 052, 504v-575v; pp. 11-16. 
gotas". En esta situación, la Junta Particular de Azcoitia de febrero de 1793 acordó suplicar licencia al Rey ${ }^{67}$ para tomar dinero a censo o interés, sobre sus propios o arbitrios, por necesidades de la guerra, y para que se eliminasen los impedimentos existentes en la Contaduría General de Propios y Arbitrios del Reino, tanto para la Provincia como para los pueblos, hasta que se amortizasen los capitales, autorizándolos con el solo conocimiento y aprobación de la Diputación. Pidió, asimismo, licencia para enajenar, en su caso, terrenos u otras fincas con los mismos fines.

Estas peticiones fueron atendidas por el Rey y, por real resolución de 4 de abril de 1793, accedió a lo solicitado por la Provincia, a excepción de a la venta de terrenos y fincas con la sola autorización de la Diputación, si bien se comprometió a agilizar los trámites.

Por las limitaciones que representaba para la Provincia la real resolución, ésta volvió a intentarlo con una nueva representación el 6 de diciembre de 1793, a la que respondió el Rey con una nueva real resolución de 16 de abril de 1794, por la cual se ratificó en la anterior comprometiéndose a agilizar los trámites ${ }^{68}$. A la vista de la misma, quedó definido el marco económico- fiscal en el que debían moverse tanto la Provincia como los pueblos. Tengasé en cuenta que aún no se había producido la invasión del territorio guipuzcoano. A continuación, señalamos algunas de las gestiones que realizó con éxito la Provincia, aunque, sin duda, hubo mucha más. Así:

— El 10 de febrero de $1794^{69}$ la Diputación ordenó al tesorero de la Provincia que se hiciese cargo de un préstamo a censo que el cabildo de Fuenterrabía le concedió, por importe de 15.000 rv.

- El 16 de abril de 1794 la Condesa de Villafuertes concedió un préstamo de 5.000 ducados a la Diputación para la Caja de la Guerra $^{70}$.

- El 18 de julio de 1794, sólo a 7 días de que los franceses iniciaran la invasión por el valle del Baztán, la Diputación ${ }^{71}$ se dirigió al Duque de la Alcudia para solicitar su apoyo a la solicitud que iba a elevar al Rey para que autorizase a la Real Compañía de Filipinas a prestar a la Provincia, a interés, hasta 100.000 pesos, pues ante la gran necesidad de medios económicos que

67 AGG-GAO JD J 105,2 p. 20.

${ }_{68}$ AMH; Libro de Actas 1794; Signatura A-1-138; doc. 13.829.

${ }^{69}$ AGG-GAO JD CO 051, 405v-482r; p.20.

${ }^{70}$ AGG-GAO JD CO 051, 642r-753v; pp. 1-2.

${ }^{71}$ AGG-GAO JD CO 052, 023r-058v; pp. 6-9. 
tenía la Provincia y sus pueblos nadie se fiaba de su solvencia y no encontraban quienes les prestasen el dinero que precisaban para hacer frente a la invasión de los franceses.

- Y el 27 de febrero de $1795^{72}$ la Diputación, desde Salinas, escribió a su Agente en Corte para indicarle que no aceptase la letra que el Marqués de Valmediano le entregó por importe de 60.000 rv. contra el administrador del Marques en la villa de Villafranca, endosado al Diputado General de la Provincia. Se contestó al Marqués que la Diputación no podía aceptar el riesgo de traer el dinero desde Villafranca, por estar esta villa fuera de su demarcación, indicándole que lo aceptaría si su administrador lo acercase a algún pueblo libre de la presencia francesa.

\section{FINANCIACIÓN DE LA GUERRA POR LOS PUEBLOS}

Con carácter general ya hemos señalado que los pueblos o repúblicas (como comúnmente se denominan) eran un todo a efectos de gobierno y financiación: tenían que organizar la vida local y proveer a los vecinos de todas sus necesidades, incluso las espirituales. La vida municipal era participativa y todos los vecinos, según su clase, podían participar en las reuniones del concejo abierto y en la elección de los concejantes, aunque la elección fuera, en última instancia, de forma indirecta. Naturalmente que las personas elegibles debían cumplir con los requisitos recogidos en el fuero, con lo que se reducía, de hecho, el número de persona elegibles; e incluso había un cierto trasiego de personas que ocupaban puestos de representación de unas repúblicas ante las Juntas, y en otras Juntas aparecían como caballeros procuradores de otras repúblicas o pueblos.

La provisión de todo tipo de bienes estaba perfectamente regulada en los pueblos: nada podía venderse si no pasaba previamente por la alhóndiga, y allí se cargaba el producto con los arbitrios que le eran aplicables, la mayoría de carácter local, aunque también los había de carácter provincial. En algunos casos se aplicaba la sisa que correspondiera u otro tipo impositivo.

Ante el incremento de los gastos que estaba originando la movilización a guerra y la imposibilidad de hacer frente a los gastos vía impuestos la Junta Particular de Azcoitia acordó en febrero de 1793 solicitar al Rey que autorizara a la Provincia y a sus repúblicas, pre-

72 AGG-GAO JD CO 052, 504v-575v; pp. 11-16. 
via autorización de la Diputación, a tomar dinero a censo redimible y a interés con la sola comunicación al Consejo, indicando características y destino, así como enajenar tierras y otras fincas cuando fuese preciso, con la autorización de la Diputación en los términos ya tratados en el punto II.8.-Dinero a censo redimible o interés.

No hemos podido encontrar de una forma precisa las cuentas de los pueblos. Téngase en cuenta que en la gran mayoría de los pueblos los años de la guerra están casi en blanco, y en algunos las hojas están arrancadas ${ }^{73}$. Los conceptos más importantes para obtener ingresos y financiación por parte de los Ayuntamientos eran los siguientes:

\section{III.1. De carácter impositivo}

Los pueblos eran soberanos, y para desarrollar su cometido tenían que recurrir a varios instrumentos impositivos y financieros tales como las sisas, los arbitrios y las rentas que obtenían de sus propios y frutos, y venta de inmuebles y fincas, así como a préstamos a interés o censo.

Los presupuestos locales tenían tendencia a equilibrarse, y cuando surgían situaciones, como la guerra que tratamos, en la que las necesidades económicas de los pueblos y de la Provincia se disparaban, los pueblos no tenían otra alternativa más que obtener autorización del Consejo o de la Provincia, o de la Diputación según los casos, para incrementar sus ingresos, subiendo impuestos, endeudándose, vendiendo o cediendo propios. Éstos son algunos ejemplos:

— La villa de Villafranca solicitó licencia ${ }^{74}$ a la Provincia para subir el arbitrio de la azumbre de vino, de 4 a 6 maravedíes, e imponer 2 rv. a la azumbre de aguardiente o mistela, para poder hacer frente a los gastos de la guerra y contribuir fogueralmente a la Caja de la Guerra.

${ }^{73}$ A título de ejemplo, vamos a exponer las cuentas de la villa de Tolosa correspondientes a los ejercicios de 1793 a 1796, de forma resumida: 1793, Cargo 86.115 r., Data 105.360 r., Alcance -19.244 r.; 1794, Cargo 33.000 r., Data 77.171 r., Alcance -44.171 r.; 1795, Cargo 0 r., Data 0 r., Alcance 0 r.; 1796, Cargo 6.876 r., Data 13.139 r., Alcance -6.263 r.

74 AGG-GAO JD DD 75.2 (año 1793); pp. 5-7. 
- El 16 de noviembre de $1794^{75}$ el alcalde de la villa de Ataun solicitó a la Diputación autorización para sufragar que los gastos de la Guerra mediante el donativo o censo, ya que las arcas municipales estaban exhaustas.

- El 16 de diciembre de $1794^{76}$ el alcalde de la villa de Anzuola solicitó a la Diputación que viese la forma de abonar a sus naturales el sobreprest del Rey, ya que el Ayuntamiento no podía hacer frente a dicho gasto, y que, en cuanto a lo acordado en la Diputación de Mondragón de 28 de agosto de 1794 (sobre que se destinase el 5\% de trigo que se abonaba al Rey al pago de dicho sobreprest), en el caso de Anzuola no era posible su abono ya que los franceses invadieron la villa y arrasaron con todo.

— La villa de la villa de Elgoibar, por su parte, se dirigió a la Diputación ${ }^{77}$ para tratar de encontrar una solución al problema que se planteó al consumir los milicianos vizcaínos el vino y aguardientes sin pasar por la alhóndiga, no contribuyendo así al sostenimiento del municipio. Igualmente sucedió con el ejército real y algunos particulares ${ }^{78}$.

El 2 de febrero de 1794 la Diputación contestó a la villa de Mondragón $^{79}$ (a la pregunta de si en la situación actual estaban exentos los miembros e instituciones religiosas de pagar impuestos) que, en la medida en que el Rey no dispusiese otra cosa, los nuevos arbitrios que se impusiesen para financiar la guerra no afectaban a los eclesiásticos ni a las comunidades regulares, por gozar de privilegio, pero que si dichos arbitrios se dirigían a defender la religión sí les afectaban.

En caso de darse alguna situación extraordinaria derivada de la Guerra, la Provincia actuaba de forma particular. En concreto, la Junta Particular de Mondragón de septiembre de $1794^{80}$ trató, en su punto $\mathrm{n}^{\circ} 10$, la problemática generada en la mayoría de los pueblos de la existencia de personas desamparadas a consecuencia de la Guerra. Y para mitigar sus efectos, acordó que las personas pro-

75 AGG-GAO JD DD 76.1 (1794), 62r-88v; p. 20.

76 AGG-GAO JD DD 76.1 (1794), 62r-88v; pp. 31-33.

77 AGG- GAO JD DD 77.1, 01r-19v; pp. 28-29.

${ }^{78}$ El Ayuntamiento de Elgoibar grababa: $20 \mathrm{mrv}$. por azumbre de vino; $17 \mathrm{mrv}$. por azumbre de aguardiente y mistela; 4 mrv. por azumbre de vino con destino a financiar la guerra. Además de lo anterior, pagaba: $4 \mathrm{mrv}$. para suplemento de gastos corrientes; 4 mrv. para el donativo gracioso de la Diputación; y 8 mrv. para réditos censales de los nuevos caminos.

${ }^{79}$ AGG-GAO JD CO 051, 405v-482r; pp. 24-25.

80 AGG-GAO JD AJ I05,4; pp. 20-24. 
pietarias de fincas y rentas deberían contribuir a las arcas municipales de sus respectivos municipios con el 5\% de la cosecha o renta obtenida.

Igualmente acordó que las personas acaudaladas contribuyesen en los mismos términos que las personas que tuviesen fincas o rentas. Las comunidades eclesiásticas deberían contribuir entregando las primicias de las iglesias, deducidos los gastos. Y para ello se dirigieron a los Obispos de Pamplona y Calahorra-La Calzada solicitando su aprobación, y así lo hicieron.

\section{III.2. Renta de los propios}

Los municipios disponían de las rentas de sus propios (bienes cuya titularidad era del pueblo), y sus aprovechamientos se almonedaban y arrendaban en pública subasta "a candela encendida". Dichos propios consistían en edificios, molinos, tejerías, ferrerías, montes y fincas para sembrar, prados, castañales, etc., pues los pueblos tenían la titularidad de la propiedad de la mayoría de los campos y bosques y una buena parte de sus edificaciones.

\section{III.3. Venta de propios}

La venta de los propios de los pueblos estaba muy restringida por el Consejo Real, ya que estos bienes eran un medio seguro de supervivencia de la comunidad que los poseía, y el Rey velaba para que no cayeran en manos de los poderosos en tiempos de necesidad de los pueblos, si bien con el tiempo los poderosos acrecentaron su activo a costa de los mismos por causa de las necesidades temporales de los pueblos.

\section{III.4. Solicitar dinero a censos redimibles.}

Los pueblos, al igual que la Provincia, para atender a sus necesidades no corrientes acudían a obtener medios económicos a censo o interés, dando fincas en garantía, que sujetaban la seguridad de los préstamos o censos. Normalmente los prestamistas eran las iglesias, sacerdotes, obispos o instituciones religiosas, aunque también lo fueron ciertas personas que disponían de fortuna y, en algunos casos, querían dejar al fallecer en buena posición a determinadas personas físicas o jurídicas; y ello se hacía con la seguridad de que 
dichos préstamos estaban sujetos a determinadas fincas como garantía. La autorización para realizar estas operaciones económicas las daba el Consejo, bajo el control de la Contaduría General de Propios y Arbitrios del Reino, cuyo procedimiento era largo y engorroso. Igual procedimiento se seguía si el pueblo tenía que recurrir a la venta de sus propios. A la vista de la situación creada por los preparativos de la guerra, la Provincia convocó Junta Particular en la villa de Azcoitia, para los días 21-24 de febrero de 1793, a fin de tomar las oportunas decisiones. Entre las que se tomaron estaba una que pretendía paliar las necesidades económicas de los pueblos, e incluso de la Provincia, que consistía en hacer más viable la obtención de créditos a censo o a interés para poder acometer los gastos de la guerra sustituyendo la preceptiva autorización del Consejo por la de la Diputación, en los términos que hemos señalado al tratar el mismo tema para la Provincia.

\section{LAS CUENTAS GENERALES DE LA PROVINCIA DURANTE LOS AÑOS 1792-1798.}

Se han analizado las cuentas presentadas a las Juntas Provinciales de los años 1792 a 1798 y de las mismas se extraen una serie de conclusiones que parecen muy interesantes en cuento al formato, al contenido y, sobre todo, las constantes que mantienen. Todas las cuentas arrancan con la recaudación que aportan los pueblos del donativo gracioso, que era el principal aporte de medios de la Provincia con que llevar a cabo su cometido, y gravaba el consumo, principalmente vino, mistela y aguardiente. Mediante este recurso los pueblos aportaron aproximadamente unos $300.000 \mathrm{rv}$. anuales a las arcas de la Provincia.

Los ingresos de la Provincia derivaban de muy pocas fuentes:

a. Donativo gracioso

b. Dinero a interés o a censo que obtiene.

c. Reventa de alimentos (trigo)

d. Dividendos de inversiones (Real Compañía de Filipinas)

f. Otros menores y circunstanciales.

Todos estos conceptos integraban lo denominado en las cuentas como "Cargo", que reflejaba todos los ingresos obtenidos. 
Por contraposición, el termino de "Data" integraba todos los conceptos de gasto que tenía la Provincia. Los más habituales eran:

a. Abono de intereses de los créditos.

b. Capitales redimidos (amortización de créditos)

c. Pago de causas criminales.

d. Abono de servicios prestados por cuenta de la Provincia.

e. Sueldos de funcionarios y empleados.

f. Abonos de levas de marineros para la Armada.

g. Gastos de Juntas Generales.

Podríamos decir que en la cuenta de Cargo en el periodo analizado de 1792 a 1798, el donativo gracioso aportó del orden del 80\% de los ingresos, excepto en las cuentas de 1793, en las que hubo un préstamo a la Provincia de 60.000 rv. por un particular; y por el contrario, en 1797 se amortizó un préstamo de un particular de 65.000rv. Lo comentado al respecto se dio en situaciones normales, porque los años 1795 y 1796 no se presentaron las cuentas al estar en guerra, presentándose al año siguiente. Pero en este caso, el donativo realmente recaudado no llegó al $20 \%$ de lo señalado, siendo sustituido dicho ingreso por las aportaciones que venían de Madrid en concepto de dividendo y abono de los intereses y capital en la Real Compañía de Filipinas.

Llama mucho la atención el hecho de que al comenzar los movimientos que permitían presagiar una guerra con Francia en 1792, el endeudamiento normal de la Provincia era de unos 3.800.000 rv., por los que abonaba unos intereses medios de 65.000 rv.; es decir, la Provincia obtenía el dinero a una tasa de interés medio del 1,7\% anual, y durante la guerra en las cuentas no consta ningún endeudamiento complementario y, por otra parte, no hemos encontrado rastro alguno de la Caja de Guerra ni datos de la aprobación de sus cuentas. Sí que hemos encontrado la cuenta de la alcaldía de sacas, la cuenta del Agente en Corte y la cuenta de las obras de los caminos.

\section{CONCLUSIONES}

La Guerra de la Convención entre España y Francia afectó de una forma importante a la Provincia de Guipúzcoa y a sus pueblos. Matización relevante, ya que los pueblos de Guipúzcoa, según el 
fuero, debían armar, equipar y sostener a sus Compañías movilizadas en defensa de su Dios, su Rey y su Patria.

La Provincia, por su parte, debía hacer frente a gastos de la guerra con unos medios económicos provenientes de inversiones de la propia Provincia, de arbitrios y de censos, además de la aportación fogueral que hacían los pueblos.

Tanto la Provincia como los pueblos partían de una situación de endeudamiento muy importante, debido a que tuvieron que construir sus caminos reales a lo largo de unos $200 \mathrm{~km}$. En esta situación de endeudamiento se declaró la guerra, debiendo movilizar a más de 8.000 hombres, a cuyos gastos Guipúzcoa, escasa de recursos y hombres, tuvo que hacer frente.

Los medios de que se valieron las instituciones para cumplir sus obligaciones consistieron en incrementar la recaudación impositiva y los rendimientos de los activos, en solicitar donativos, endeudarse aún más y, sobre todo, obtener (a reintegro) una buena parte de la plata de la iglesias y conventos, así como rentas de instituciones religiosas. 